\title{
Genetic polymorphisms of NAT2, CYP2E1 and GST enzymes and the occurrence of antituberculosis drug-induced hepatitis in Brazilian TB patients
}

\author{
Raquel Lima de Figueiredo Teixeira', Renata Gomes Morato', \\ Pedro Hernan Cabello ${ }^{1}$, Ligia Mayumi Kitada Muniz ${ }^{2}$, Adriana da Silva Rezende Moreira ${ }^{2}$, \\ Afrânio Lineu Kritski², Fernanda Carvalho Queiroz Mello², Philip Noel Suffys ${ }^{3}$, \\ Antonio Basilio de Miranda ${ }^{4}$, Adalberto Rezende Santos ${ }^{3 /+}$
}

\author{
12Laboratório de Genética Humana ${ }^{3}$ Laboratório de Biologia Molecular Aplicada a Micobactérias \\ ${ }^{4}$ Laboratório de Biologia Computacional e Sistemas, Instituto Oswaldo Cruz-Fiocruz, Av. Brasil 4365, 21040-360 Rio de Janeiro, RJ, Brasil \\ ${ }^{2}$ Programa Acadêmico de Tuberculose, Instituto de Doenças do Tórax, Hospital Universitário Clementino Fraga Filho, \\ Complexo Hospitalar, Faculdade de Medicina, Universidade Federal do Rio de Janeiro, Rio de Janeiro, RJ, Brasil
}

\begin{abstract}
Isoniazid (INH), one of the most important drugs used in antituberculosis (anti-TB) treatment, is also the major drug involved in hepatotoxicity. Differences in INH-induced toxicity have been attributed to genetic variability at several loci, such as NAT2, CYP2E1, GSTM1 and GSTT1, that code for drug-metabolising enzymes. Our goal was to examine the polymorphisms in these enzymes as susceptibility factors to anti-TB drug-induced hepatitis in Brazilian individuals. In a case-control design, 167 unrelated active tuberculosis patients from the University Hospital of the Federal University of Rio de Janeiro, Brazil, were enrolled in this study. Patients with a history of anti-TB drug-induced acute hepatitis (cases with an increase to 3 times the upper limit of normal serum transaminases and symptoms of hepatitis) and patients with no evidence of anti-TB hepatic side effects (controls) were genotyped for NAT2, CYP2E1, GSTM1 and GSTT1 polymorphisms. Slow acetylators had a higher incidence of hepatitis than intermediate/rapid acetylators [22\% (18/82) vs. 9.8\% (6/61), odds ratio (OR), 2.86, 95\% confidence interval (CI), 1.06-7.68, $p=0.04$ ). Logistic regression showed that slow acetylation status was the only independent risk factor (OR 3.59, 95\% CI, 2.53-4.64, $p=0.02$ ) for the occurrence of anti-TB drug-induced hepatitis during anti-TB treatment with INH-containing schemes in Brazilian individuals.
\end{abstract}

Key words: hepatotoxicity - tuberculosis - isoniazid - NAT2 - CYP2E1 - GSTM1 - GSTT1

Tuberculosis (TB) is one of the major causes of illness and death worldwide, especially in Asia and Africa. Globally, 9.2 million new cases and 1.7 million deaths from TB occurred in 2006, of which 0.7 million cases and 0.2 million deaths were in human immunodeficiency virus (HIV)-positive individuals (WHO 2008). Brazil is 16th among the 22 countries with the highest burden of $\mathrm{TB}$, with 50 million infected subjects, 110,000 new cases and 6,000 annual deaths (Santos-Filho 2006, MS 2007).

According to the guidelines for TB control, treating patients with antituberculosis (anti-TB) drugs is one of the most effective interventions and schemes containing isoniazid (INH), rifampicin, ethambutol and pyrazinamide are used as first-line TB therapy (Santos-Filho 2006, WHO 2008). Despite the availability of effective

Financial support: FAPERJ/PRONEX (E-26/170.0003/2008), FAPERJ Pensa Rio (E-26/110.288/2007), CNPq (308786/2005-0, 350477/1995-7, 306702/2007-0 and 312165/2006-4 to ARS, ALK, FCQM and PNS, respectively)

+ Corresponding author: adalbertorezende@yahoo.com.br

Received 1 March 2011

Accepted 14 July 2011 chemotherapeutic agents to treat TB, side effects such as hepatic disorder and peripheral neuritis are frequent, which limits the clinical use of the drugs and contributes to treatment relapse and the appearance of multidrugresistant Mycobacterium tuberculosis strains (Garibaldi et al. 1972, Frieden et al. 2003).

The most frequent and serious side effect of these drugs is hepatotoxicity (Garibaldi et al. 1972, Saukkonen et al. 2006). The liver has a central role in drug metabolism and detoxification and is consequently vulnerable to injury. Among the first line anti-TB drugs, INH is mainly responsible for the occurrence of drug-induced hepatic adverse effects and the metabolic intermediates of INH appear to be the cause of hepatotoxicity (Mitchell et al. 1976, Nelson et al. 1976, Woodward \& Timbrell 1984). In the liver, INH is metabolised to acetylisoniazid via $\mathrm{N}$-acetyltransferase 2 (NAT2) and is followed by hydrolysis to acetylhydrazine. Acetylhydrazine is oxidised by cytochrome P4502E1 (CYP2E1) to form hepatotoxic intermediates (Nelson et al. 1976, Timbrell et al. 1980). These reactive metabolites can destroy hepatocytes either by interfering with cell homeostasis or by triggering immunologic reactions in which reactive metabolites that are bound to hepatocyte plasma proteins may act as haptens (Lee 2003). The other metabolic pathway to generate toxic metabolites is the direct hydrolysis of INH to hydrazine, a potent hepatotoxin. NAT2 is also responsible 
for converting acetylhydrazine to diacetylhydrazine, a nontoxic component (Mitchell et al. 1976, Nelson et al. 1976, Woodward \& Timbrell 1984) (Figure). Glutathione S-transferase (GST), an important phase II detoxification enzyme, is thought to play a protective role as an intracellular free radical scavenger, which conjugates glutathione with toxic metabolites that are generated from CYP2E1 (Sodhi et al. 1996). Sulphydryl conjugation facilitates the elimination of metabolites from the body and reduces the toxic effect (Hayes et al. 2005) (Figure).

The common risk factors for hepatitis include advanced age, sex, malnutrition, complications of diseases, alcohol abuse, HIV infection and viral hepatitis B and C infections (Kimmoun \& Samuel 2002, Saukkonen et al. 2006, Yew \& Leung 2006). Recent studies have demonstrated that genetic polymorphisms in drug-metabolising enzymes, which influence their activation capacity and the generation of metabolites in the liver, might predispose an individual to hepatic adverse reactions (Ohno et al. 2000, Kita et al. 2001, Roy et al. 2001, Hiratsuka et al. 2002, Huang et al. 2002, 2003, 2007, Roy et al. 2006, Leiro et al. 2008).

NAT2 is a polymorphic gene and single nucleotide polymorphisms (SNPs) in its coding region can alter its enzymatic activity (Fretland et al. 2001, Zang et al. 2007). In fact, three major genetically determined phenotypes are observed: rapid, intermediate and slow acetylators, which are inherited as codominant traits (Parkin et al. 1997, Kinzig-Schippers et al. 2005, Chen et al. 2006). The reference $N A T 2 * 4$ allele and 62 other variants of the NAT2 gene were identified and classified in human populations depending on the combination of up to four SNPs present throughout the NAT2 coding region (louisville. edu/medschool/pharmacology/NAT.html). Currently, a total of 38 SNPs have been identified in the NAT2 coding region, including several rare SNPs described in different populations (Teixeira et al. 2010). Many studies have demonstrated that people with low NAT2 activity have a higher risk of developing hepatic disorders than those with high NAT2 activity (Ohno et al. 2000, Kita et

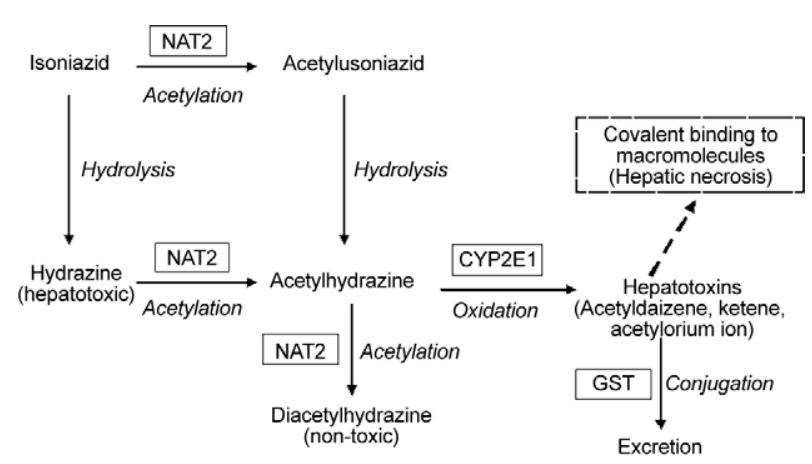

Isoniazid (INH) metabolism in the liver. Schematic representation of the INH metabolism. In liver, INH is metabolized to acetylisoniazid via $\mathrm{N}$-acetyltransferase 2 (NAT2), followed by hydrolysis to acetylhydrazine. Acetylhydrazine is oxidized by cytochrome P4502E1 (CYP2E1) to form hepatotoxic intermediates. The major enzymes involved in this pathway are indicated in boxes (Mitchell et al. 1976, Roy et al. 2008). GST: glutathione S-transferase. al. 2001, Hiratsuka et al. 2002, Huang et al. 2002). However, other authors have observed that rapid acetylation is a risk factor for anti-TB drug-induced hepatitis and the controversy still remains (Mitchell et al. 1975, Singh et al. 1995a, b, Vuilleumier et al. 2006).

The activity of CYP2E1 is also modulated by polymorphisms at several sites in the gene and higher activity of this enzyme may increase the synthesis of hepatotoxins and lead to hepatotoxicity. Two polymorphisms upstream of the CYP2E1 transcriptional start site are detectable by $P s t \mathrm{I}$ and $R s a$ I restriction enzymes and appear to be in complete linkage disequilibrium. Three genotypes of CYP2E1 are classified as $* 1 A / * 1 A, * 1 A / * 5$ and $* 5 / * 5$ by restriction fragment length polymorphism (RFLP) using $R s a$ I as the restriction enzyme (cypalleles.ki.se/ index.htm). The presence of $C Y P 2 E 1 * 1 A / * 1 A$ as a genetic marker of anti-TB drug-induced liver injury has been evaluated in a few studies with discordant results (Huang et al. 2003, Vuilleumier et al. 2006, Cho et al. 2007).

The absence of GST activity due to homozygous null mutations at the GSTM1 and GSTT1 loci may also modulate susceptibility to drug-induced hepatitis, but the results reported in the literature are not homogenous (Roy et al. 2001, Huang et al. 2007, Leiro et al. 2008).

Due to differences in NAT2, CYP2E1, GSTM1 and GSTT1 genotype frequencies among ethnic groups, evaluation of these genetic markers in the predisposition to drug-induced hepatitis during TB treatment is needed in admixed populations. Brazilians are members of one of the most heterogeneous population in the world, which is the result of five centuries of ethnic admixture of people from three continents: the European colonisers mainly represented by the Portuguese, the African slaves and the autochthonous Amerindians. Pharmacogenetic studies in this kind of population have important implications because the extrapolation of the data derived from well-defined ethnic groups is clearly not applicable. Recognising the diversity of the distribution of the genes and the high incidence of TB in Brazil, we have reported here the contribution of the NAT2, CYP2E1, GSTM1 and GSTT1 genetic variants to the susceptibility to anti-TB drug-induced hepatitis in TB patients.

\section{PATIENTS, MATERIALS AND METHODS}

Study design and patients - In a case-control design, a total of 167 unrelated active TB patients who had been treated between 1998-2008 were enrolled in this study. The patients had received treatment at the University Hospital Complex, Thoracic Institute/Clementino Fraga Filho University Hospital, Federal University of Rio de Janeiro, Brazil. This public hospital is a reference centre for HIV and other co-morbidities. Annually, approximately 150 TB cases are reported, of which $26 \%$ are infected by HIV, $13 \%$ have other co-morbidities (cancer, transplant, use of immunessupressors) and $8 \%$ have hepatitis or drug-induced hepatotoxicity.

We retrospectively identified all of the patients who developed anti-TB drug-induced acute hepatitis (cases) and those who showed no evidence of anti-TB hepatic side effects (controls). The enrolled patients were genotyped to identify the genetic risk factors (polymorphisms 
in NAT2, CYP2E1, GSTM1 and GSTT1) associated with the susceptibility to anti-TB drug-induced hepatitis in Brazilian individuals.

This study was approved by the Ethical Committee of the Oswaldo Cruz Foundation and written informed consent was obtained from all of the enrolled patients.

Patients were selected using the following criteria: (i) age above 18 years, (ii) diagnosis of active TB, (iii) treatment with anti-TB drug regimens that include INH at the usual dosage (400 mg/day) and (iv) normal baseline serum transaminases [alanine aminotransferase (ALT) and aspartate aminotransferase (AST)] before treatment for inclusion and (v) positive serological test for the HIV, hepatitis B virus or hepatitis C virus, (vi) alcohol abuse, (vii) history of chronic liver disease and (viii) pregnancy for exclusion. A volume of $3 \mathrm{~mL}$ of venous blood was collected from each volunteer and stored at $-20^{\circ} \mathrm{C}$. Genomic DNA was isolated from $100 \mu \mathrm{L}$ of frozen whole blood using the FlexiGene DNA Kit (Qiagen Inc, USA) according to the manufacturer's specifications. After extraction, DNA samples were stored at $-20^{\circ} \mathrm{C}$.

Liver function monitoring and the diagnosis of druginduced adverse effects - Liver function tests, consisting of serum transaminases, total bilirubin and alkaline phosphatase measurements were performed once a month, during the patient's visit, using commercial kits according to the manufacturer's instructions. The following values were considered to be normal for the different tests: ALT 30-65 IU/L, AST 15-37 IU/L, total bilirubin up to $1 \mathrm{mg} / \mathrm{dL}$ and alkaline phosphatase 50-136 IU/L. Clinical and laboratory checkups were performed more frequently when hepatitis symptoms or abnormal serum transaminases levels were observed.

According to the American Thoracic Society criteria (Saukkonen et al. 2006) and the Brazilian Health Ministry, cases are those individuals who showed anti-TB drug-induced hepatitis by an increase in serum transaminase values to higher than three times the upper limit of normal values ( $>3 \times$ ULN) and symptoms compatible with hepatitis.

NAT2 genotyping and haplotype reconstruction Genotyping of the NAT2 coding region and computational analysis were performed as previously described (Teixeira et al. 2007). In brief, a 1,093-bp fragment, which contains the entire coding region of NAT2, was amplified by polymerase chain reaction (PCR) and subsequently sequenced on both DNA strands using the primers for amplification and two additional internal primers (Teixeira et al. 2007). Sequencing was performed using the ABI PRISM BigDye Terminator v. 3.1 Kit (PE Applied Biosystems) according to the manufacturer's recommendations on an ABI PRISM 3730 DNA Analyser (PE Applied Biosystems). The sequence analysis and SNP identification were performed using SeqScape Software v.2.5 (PE Applied Biosystems) with the sequence (GenBank: AY331807) as the reference. To solve the haplotype pair of each patient and to define the acetylation status, haplotype reconstruction was performed using the program PHASE v2.1.1 (Stephens et al. 2001, Stephens \& Donnelly 2003) with the default model for recombination rate variation (Li \& Stephens 2003). Five independent runs with 1,000 interactions, 500 burn-in interactions and a thinning interval of one were performed. The best run that showed the maximum consistency across five runs was chosen. Additionally, the consistency of the results that applied the PHASE algorithm repeatedly with default and varying values of the number of interactions, burn-in interactions and the thinning interval was pursued.

CYP2E1 genotypes identification - To genotype the SNP $-1053 \mathrm{C}>\mathrm{T}$ in the CYP2E1 gene promoter region and to determine the three genotypes $(* 1 \mathrm{~A} / * 1 \mathrm{~A} ; * 1 \mathrm{~A} / * 5$ and *5/*5), a PCR with the amplification primers CYP2E1F 5'CCAGTCGAGTCTACATTGTCA3' and CYP2E1R 5'TTCATTCTGTCTTCTAACTGG3' were performed followed by RFLP as previously described (Stephens et al. 1994). Briefly, after the amplification of a 413-bp DNA fragment flanking the $-1053 \mathrm{C}>\mathrm{T}$ SNP, the PCR product was digested with the $R s a$ I restriction enzyme. Evaluation of the fragment digestions was achieved by electrophoresis on a $2 \%$ agarose gel followed by ethidium bromide staining $(0.5 \mu \mathrm{g} / \mathrm{mL})$.

GSTT1 and GSTM1 genotype identification - To determine the presence or absence of the GSTM1 and GSTT1 genes, two separate multiplex PCR reactions were performed as previously reported with minor modifications (Bailey et al. 1998, Sprenger et al. 2000). The GSTM1 wild-type allele $(+)$ was identified by the PCR method using primers M1 5'CTGCCCTACTTGATTGATGGG3' and M2 5'CTGGATTGTAGCAGATCATGC3' to obtain a 273-bp PCR product (Bailey et al. 1998). Co-amplification of a 536-bp fragment of the $\beta$-globin gene using the primers Betal 5'GGTTGGCCAATCTACTCCCAGG3' and Beta2 5'GCTCACTCAGTGTGGCAAAG3' was performed as an internal control. The PCR reaction mixture was performed in a total volume of $50 \mu \mathrm{L}$ containing $100 \mathrm{ng}$ of genomic DNA, $240 \mathrm{ng}$ of each GSTM1 primer and 10 pmoles of each $\beta$-globin primer, PCR Gold buffer (1x), $3 \mathrm{mM} \mathrm{MgCl}$, $0.1 \%$ Triton X-100, $0.2 \mathrm{mM}$ of each dNTP and 2U AmpliTaq Gold ${ }^{\circledR}$ DNA polymerase (PE Applied Biosystems). Amplification conditions consisted of an initial denaturing step of $95^{\circ} \mathrm{C}$ for $10 \mathrm{~min}$, followed by 30 cycles of $95^{\circ} \mathrm{C}$ for $30 \mathrm{~s}, 64^{\circ} \mathrm{C}$ for $1 \mathrm{~min}$ and $72^{\circ} \mathrm{C}$ for $6 \mathrm{~min}$. The homozygous GSTM1 null genotype (-/-) was detected by the absence of the 273bp fragment. Individuals who presented with the 273-bp fragment were classified as $+/-(+/+$ or $+/-)$ and contained at least one wild-type allele.

For GSTT1 genotyping and identification of the three genotypes (GSTT1*A/GSTT1*A, GSTT1*A/GSTT1*0 and GSTT1*0/GSTT1*0), a 1,460-bp GSTT1* 0 specific fragment was co-amplified with a 460-bp fragment corresponding to the $G S T T 1^{*} A$ allele in a single reaction tube using primers T1 5'CCAGCTCACCGGATCATGGCCAG3', T2 5'GAGATGTGAGGACCAGTAAGGAAGG3', T3 5'CAGTTGTGAGCCACCGTACCC3' and T4 5'GAGGGGGCCAGCAACTATCG3' (Sprenger et al. 2000). PCR was performed in a $50 \mu \mathrm{L}$ reaction mix containing $150 \mathrm{ng}$ genomic DNA, PCR buffer (1x), $100 \mathrm{ng}$ of each primer, $1.5 \mathrm{mM} \mathrm{MgCl}, 100 \mu \mathrm{g} / \mathrm{mL}$ bovine serum 
albumin, $0.2 \mathrm{mM}$ of dNTPs and 2U DNA polymerase (Biotools, Madrid/Spain). Amplification conditions consisted of a touchdown PCR with an initial denaturing step $\left(94^{\circ} \mathrm{C}\right.$ for $\left.5 \mathrm{~min}\right)$ followed by 20 cycles of $94^{\circ} \mathrm{C}$ for $1 \mathrm{~min}, 68^{\circ} \mathrm{C}$ for $1 \mathrm{~min}$ (with a decrease of $0.5^{\circ} \mathrm{C}$ per cycle at the annealing temperature) and $72^{\circ} \mathrm{C}$ for $1 \mathrm{~min}$ and $30 \mathrm{~s}$. An additional 15 cycles of $94^{\circ} \mathrm{C}$ for $1 \mathrm{~min}, 58^{\circ} \mathrm{C}$ for $1 \mathrm{~min}$ and $72^{\circ} \mathrm{C}$ for $1.5 \mathrm{~min}$ were performed. Evaluation of the PCR amplicons was achieved by electrophoresis on a $2 \%$ agarose gel followed by ethidium bromide staining.

Statistical analysis - Data are expressed as the mean \pm standard deviation (for normal distribution) or as the median with range (for non-normal distribution). Expected genotype frequencies were calculated from the respective single allele frequencies according to the Hardy-Weinberg equation. The observed and expected gene frequencies were compared using a $\chi^{2}$ test for Hardy-Weinberg equilibrium, except for the GSTM1 genotype, for which the heterozygous frequency was not determined.

Qualitative variables were compared using a $\chi^{2}$ test with Yates correction or Fisher's exact test when appropriate. Quantitative variables were analysed using Student's $t$ test for normal distribution or Mann-Whitney $U$-test (2 groups) and Kruskal-Wallis test (up to 2 groups) for non-normal distribution. Odds ratios (OR) and confidence intervals (CI) were calculated to evaluate the susceptibility of NAT2 haplotypes, genotypes and inferred acetylation status to anti-TB drug-induced hepatic adverse effects. Multivariate analysis was performed to evaluate the adjusted risk of anti-TB drug-induced hepatic adverse effects in the different genotypes using a stepwise logistic regression analysis. All of the analyses were performed using the statistical software SPSS 12.0 for Windows (SPSS Inc, Chicago, IL). All of the statistical tests were evaluated at a 0.05 significance level.

\section{RESULTS}

Among the 167 individuals enrolled in this study, 26 were diagnosed with anti-TB drug-induced hepatitis. No statistical differences in age, sex and basal liver function tests between the cases and controls were observed (Table I). The medians of ALT, AST and total bilirubin during treatment were significantly different between the cases and controls, showing clinically significant liver injury among cases (Table I).

The CYP2E1 and GSTT1 genotypes under investigation were in Hardy-Weinberg equilibrium $(\mathrm{p}>0.05)$. No significant differences in the frequencies of CYP2E1, GSTM1 and GSTT1 genotypes existed between the cases and the controls (Table II).

After NAT2 sequencing and haplotype pair reconstruction, 14 NAT2 alleles were identified, of which two were new and are described here for the first time (Table III). Although the distribution of the NAT2 alleles between the cases and controls was not statistically different, the alleles with low activity were more frequent in cases, while the functional alleles were more frequent in the control group (Table IV). The genotypes of eight individuals $(4.8 \%)$ could not be solved after the reconstruction by PHASE v2.1.1. In addition, we identified 10 other individuals for whom the acetylation status has not yet been characterised (Table IV). Therefore, a total of $18(10.8 \%)$ individuals were excluded from the NAT2 analysis.

\section{TABLE I}

Demographic, clinical and laboratory data of the enrolled subjects and distribution of CYP2E1, GSTT1 and GSTM1 genotypes in presence or absence of hepatitis

\begin{tabular}{|c|c|c|c|}
\hline & \multicolumn{2}{|c|}{$\begin{array}{c}\text { Hepatitis } \\
(>3 \times \text { ULN AST or ALT) }\end{array}$} & \multirow[b]{2}{*}{$\mathrm{p}$} \\
\hline & $\begin{array}{l}\text { Presence } \\
(\mathrm{n}=26)\end{array}$ & $\begin{array}{l}\text { Absence } \\
(\mathrm{n}=141)\end{array}$ & \\
\hline Age (year) (mean \pm standard deviation) & $47.58 \pm 20.07$ & $42.99 \pm 14.94$ & $0.275^{a}$ \\
\hline $\operatorname{Sex}(M / F)$ & $16 / 10$ & $74 / 67$ & $0.395^{b}$ \\
\hline \multicolumn{4}{|l|}{ Baseline [median (range)] } \\
\hline AST & $27(14-54)$ & $24(10-73)$ & $0.577^{c}$ \\
\hline ALT & $31(14-95)$ & $28(10-73)$ & $0.441^{c}$ \\
\hline Total bilirubin & $0.5(0.2-1.0)$ & $0.5(0.1-1.0)$ & $0.211^{c}$ \\
\hline Alkaline phosphatase & $80.5(43-174)$ & $84.5(10-210)$ & $0.787^{c}$ \\
\hline \multicolumn{4}{|c|}{ During antituberculosis treatment [median (range)] } \\
\hline Peak AST & $351.5(74-2.600)$ & $28.5(13-108)$ & $<0.001^{c}$ \\
\hline Peak ALT & $254(60-1.331)$ & $34(13-155)$ & $<0.001^{c}$ \\
\hline Peak total bilirubin & $3.9(0.6-22.6)$ & $0.6(0.2-7.5)$ & $<0.001^{c}$ \\
\hline Peak alkaline phosphatase & $154(54-591)$ & $163(60-450)$ & $0.884^{c}$ \\
\hline
\end{tabular}

$a$ : Student's $t$ test; $b: \chi^{2} ; c$ :Mann Whitney test. Normal intervals: aspartate aminotransferase (AST): 15-37 U/L; alanine aminotransferase (ALT): 30-65 U/L; total bilirubin: $<1 \mathrm{mg} / \mathrm{dL}$; alkaline phosphatase: 50-136 U/L; ULN: upper limit of normal values. 
TABLE II

Distribution of CYP2E1, GSTT1 and GSTM1 genotypes in presence or absence of hepatitis

\begin{tabular}{lccc}
\hline & \multicolumn{2}{c}{ Hepatitis } \\
& $(>3 \times$ ULN AST or ALT $)$ & \\
\cline { 2 - 3 } & $\begin{array}{c}\text { Presence } \\
(\mathrm{n}=26) \\
\mathrm{n}(\%)\end{array}$ & $\begin{array}{c}\text { Absence } \\
(\mathrm{n}=141) \\
\mathrm{n}(\%)\end{array}$ & $\mathrm{p}$ \\
\hline CYP2E1 & & & \\
$* 1 \mathrm{~A} / * 1 \mathrm{~A}$ & $23(88.5)$ & $128(90.8)$ & 0.064 \\
$* 1 \mathrm{~A} / * 5$ & $2(7.7)$ & $13(9.2)$ & \\
$* 5 / * 5$ & $1(3.8)$ & $0(0)$ & \\
GSTT1 & & & \\
$+/+$ & $9(34.6)$ & $37(26.2)$ & 0.666 \\
$+/-$ & $13(50)$ & $77(54.6)$ & \\
-/- & $4(15.4)$ & $27(19.2)$ & \\
GSTM1 & & & \\
$+/-(+/+$ or $+/-)$ & $15(41.7)$ & $80(56.7)$ & 0.928 \\
$-/-$ & $11(42.3)$ & $61(43.3)$ & \\
\hline
\end{tabular}

ALT: alanine aminotransferase; AST: aspartate aminotransferase; ULN: upper limit of normal values. $p$ value of $\chi^{2}$.

TABLE III

NAT2 allelic frequencies among

Brazilians tuberculosis patients enrolled in this study

\begin{tabular}{lcccc}
\hline Allele & Haplotype $^{a}$ & Phenotype & Total & HepMed $^{b}$ \\
\hline NAT2*6A & GTTACAGAAGG & Slow & 24.2 & 28.8 \\
NAT2*5B & GCCATGGAGGG & Slow & 23 & 26.9 \\
NAT2*4c & GCTACGGAAGG & Rapid & 18.9 & 13.5 \\
NAT2*5A & GCCATGGAAGG & Slow & 12 & 9.6 \\
NAT2*7B & GTTACGGAAGA & Slow & 4.5 & 7.7 \\
NAT2*14B & ATTACGGAAGG & Slow & 3 & 3.8 \\
NAT2*12A & GCTACGGAGGG & Rapid & 2.4 & 0 \\
NAT2*5C & GCCACGGAGGG & Slow & 2.7 & 3.8 \\
NAT2*13A & GTTACGGAAGG & Rapid & 1.5 & 0 \\
NAT2* 5N & GCCCTGGAGGG & ND & 0.3 & 0 \\
NAT2 $*$ H & GTTACAGGAGG & ND & 0.9 & 1.9 \\
NAT2*12G & GCTACGTAGGG & ND & 0.6 & 0 \\
NAT2*6O & GTTACAGAAAG & ND & 0.9 & 0 \\
NAT2*7E & GTTATGGAAGA & ND & 0.3 & 0 \\
ND & & ND & 4.8 & 3.8 \\
\hline Total & & & 100 & 100 \\
\hline
\end{tabular}

$a$ : nucleotide positions within NAT2 coding region: 191, 282, $341,472,481,590,609,766,803,838,857 ; b$ : allele frequency among individuals with hepatitis $(\mathrm{n}=26)$; $c$ : reference allele; ND: not determined.
Of the 149 remaining individuals analysed for the NAT2 acetylation status, 82 (55.03\%) were slow acetylators, $60(40.27 \%)$ were intermediate acetylators and only seven $(4.7 \%)$ individuals showed rapid acetylation genotypes. The slow acetylators had higher median serum ALT and AST levels than rapid/intermediate acetylators during the treatment (ALT: $\mathrm{p}=0.03$; AST: $\mathrm{p}=0.01$ ). No association of any specific NAT2 genotype with susceptibility for the occurrence of anti-TB drug-induced hepatitis was present (Table IV). The risk of anti-TB drug-induced hepatitis occurrence was significantly higher in slow acetylators than in rapid/intermediate acetylators $(22 \%$ vs. 9\%, OR 2.86, 95\% CI, 1.06-7.68, p=0.04) (Table IV).

Variables such as age, sex, acetylation status and CYP2E1, GSTM1 and GSTT1 genotypes were further analysed in a multivariate logistic regression model. After adjustment, slow acetylation was the only risk factor for anti-TB drug-induced hepatitis (OR 3.59, 95\% CI, 2.53-4.64, $\mathrm{p}=0.02$ ). We have also performed similar analyses classifying individuals into three acetylation phenotypes (slow, intermediate and rapid acetylators) and observed similar results (OR 3.47, 95\% CI, 2.434.47. $\mathrm{p}=0.02$ ), which confirmed the association with only the slow acetylator phenotype.

\section{DISCUSSION}

The association of INH with hepatitis during antiTB treatment has already been reported (Steele et al. 1991, Salpeter 1993, Fountain et al. 2005). In addition, an association with other drugs with this outcome has been reported in combination with INH (Tostmann et al. 2008). NAT2, which is expressed in the liver, is the main enzyme involved in INH metabolism. In agreement with the literature data from other populations (Ohno et al. 2000, Kita et al. 2001, Hiratsuka et al. 2002, Huang et al. 2002), our findings suggest that NAT2 is the genetic factor that is responsible for the predisposition to antiTB drug-induced hepatitis in Brazilian individuals. The incidence of elevated levels of serum transaminases was significantly higher in slow acetylators than in rapid/ intermediate acetylators. These results corroborate the current hypothesis that the acetylator status may be a risk factor for the hepatic side effects of INH. Indeed, slow acetylators acetylate not only INH more slowly but also acetylhydrazine, the immediate precursor of toxic intermediates, to harmless diacetylhydrazine (Ellard \& Gammon 1976, Lauterburg et al. 1985). This protective acetylation is further suppressed by INH competition. Therefore, slow acetylators may be prone to higher accumulation rates of INH toxic metabolites. In addition, another important route for generating toxic intermediates from INH is by the direct hydrolysis of INH without acetylation (Timbrell et al. 1977). This reaction produces hydrazine, which can induce hepatic injury (Timbrell et al. 1977, 1980). Pharmacokinetic studies have shown that the serum concentration of hydrazine is significantly higher in slow acetylators than in rapid acetylators, likely due to the high concentration of INH. The high amount of INH disposed of through this pathway is likely to lead to enhanced hydrolysis to hydrazine because the rate of metabolic conversion of INH to acetylisoni- 
TABLE IV

NAT2 genotype/phenotype and susceptibility of isoniazid-induced hepatitis

\begin{tabular}{|c|c|c|c|c|c|}
\hline \multirow[b]{2}{*}{ Genotype/phenotype } & \multicolumn{2}{|c|}{ Hepatitis } & \multirow[b]{2}{*}{$\begin{array}{l}\text { Total } \\
\text { n (\%) }\end{array}$} & \multirow[b]{2}{*}{$\mathrm{OR}^{a}$} & \multirow[b]{2}{*}{$95 \% \mathrm{CI}$} \\
\hline & $\begin{array}{c}\text { Presence } \\
\text { n (\%) }\end{array}$ & $\begin{array}{c}\text { Absence } \\
\mathrm{n}(\%)\end{array}$ & & & \\
\hline Rapid acetylators & $0(0)$ & $7(5)$ & $7(4.2)$ & - & - \\
\hline NAT $2 * 4 / 4$ & $0(0)$ & $6(4.2)$ & $6(3.6)$ & - & - \\
\hline NAT2*12A/12A & $0(0)$ & $1(0.7)$ & $1(0.6)$ & - & - \\
\hline Intermediate acetylators & $6(23.1)$ & $54(38.3)$ & $60(35.8)$ & - & - \\
\hline NAT2*6A/4 & $2(7.7)$ & $18(12.8)$ & $20(12)$ & - & - \\
\hline NAT $2 * 4 / 5 \mathrm{~A}$ & $2(7.7)$ & $13(9.2)$ & $15(9)$ & - & - \\
\hline NAT $2 * 4 / 5 B$ & $0(0)$ & $8(5.7)$ & $8(4.8)$ & - & - \\
\hline NAT $2 * 12 \mathrm{~A} / 5 \mathrm{~B}$ & $0(0)$ & $4(2.8)$ & $4(2.4)$ & - & - \\
\hline NAT2*4/14B & $0(0)$ & $3(2.1)$ & $3(1.8)$ & - & - \\
\hline NAT2*7B/4 & $2(7.7)$ & $1(0.7)$ & $3(1.8)$ & - & - \\
\hline NAT2*6A/13A & $0(0)$ & $2(1.4)$ & $2(1.2)$ & - & - \\
\hline NAT2*6A/12A & $0(0)$ & $2(1.4)$ & $2(1.2)$ & - & - \\
\hline NAT2 $* 13 \mathrm{~A} / 5 \mathrm{~B}$ & $0(0)$ & $2(1.4)$ & $2(1.2)$ & - & - \\
\hline NAT2*13A/5A & $0(0)$ & $1(0.7)$ & $1(0.6)$ & - & - \\
\hline Slow acetylators & $18(69.2)$ & $64(45.4)$ & $82(49.1)$ & 2.86 & $1.06-7.68$ \\
\hline NAT2*5B/5B & $5(19.2)$ & $17(12.1)$ & $22(13.2)$ & 1.74 & $0.58-5.21$ \\
\hline NAT2*6A/6A & $3(11.5)$ & $12(8.5)$ & $15(9)$ & 1.40 & $0.37-5.36$ \\
\hline NAT2*6A/5A & $2(7.7)$ & $11(7.8)$ & $13(7.8)$ & 0.98 & $0,21-4.73$ \\
\hline NAT2*6A/5B & $3(11.5)$ & $5(3.5)$ & $8(4.8)$ & 3.55 & $0.79-15.87$ \\
\hline NAT2*7B/5A & $1(3.8)$ & $3(2.1)$ & $4(2.4)$ & - & - \\
\hline $\mathrm{NAT} 2 * 5 \mathrm{C} / 5 \mathrm{~B}$ & $0(0)$ & $4(2.8)$ & $4(2.4)$ & - & - \\
\hline NAT $2 * 6 A / 7 B$ & $0(0)$ & $3(2.1)$ & $3(1.8)$ & - & - \\
\hline NAT2*7B/5B & $1(3.8)$ & $2(1.4)$ & $3(1.8)$ & - & - \\
\hline $\mathrm{NAT} 2 * 5 \mathrm{C} / 5 \mathrm{C}$ & $1(3.8)$ & $1(0.7)$ & $2(1.2)$ & - & - \\
\hline $\mathrm{NAT} 2 * 5 \mathrm{~A} / 5 \mathrm{~B}$ & $0(0)$ & $2(1.4)$ & $2(1.2)$ & - & - \\
\hline NAT2*5A/14B & $0(0)$ & $2(1.4)$ & $2(1.2)$ & - & - \\
\hline NAT2*6A/14B & $2(7.7)$ & $0(0)$ & $2(1.2)$ & - & - \\
\hline NAT2*7B/14B & $0(0)$ & $1(0.7)$ & $1(0.6)$ & - & - \\
\hline NAT2*5B/14B & $0(0)$ & $1(0.7)$ & $1(0.6)$ & - & - \\
\hline Acetylation not determined & $2(7.7)$ & $16(11.3)$ & $18(10.8)$ & - & - \\
\hline NAT2*6H/4 & $1(3.8)$ & $0(0)$ & $1(0.6)$ & - & - \\
\hline NAT2 $* 12 \mathrm{G} / 5 \mathrm{C}$ & $0(0)$ & $1(0.7)$ & $1(0.6)$ & - & - \\
\hline NAT $2 * 6 \mathrm{H} / 5 \mathrm{~A}$ & $0(0)$ & $1(0.7)$ & $1(0.6)$ & - & - \\
\hline $\mathrm{NAT} 2 * 6 \mathrm{~A} / 6 \mathrm{H}$ & $0(0)$ & $1(0.7)$ & $1(0.6)$ & - & - \\
\hline NAT2*7B/12G & $0(0)$ & $1(0.7)$ & $1(0.6)$ & - & - \\
\hline NAT $2 * 6 \mathrm{O} / 14 \mathrm{~B}$ & $0(0)$ & $1(0.7)$ & $1(0.6)$ & - & - \\
\hline NAT2*7E/5A & $0(0)$ & $1(0.7)$ & $1(0.6)$ & - & - \\
\hline NAT $2 * 6 \mathrm{O} / 4$ & $0(0)$ & $1(0.7)$ & $1(0.6)$ & - & - \\
\hline NAT $2 * 6 \mathrm{O} / 5 \mathrm{~A}$ & $0(0)$ & $1(0.7)$ & $1(0.6)$ & - & - \\
\hline NAT2*5B/12G & $0(0)$ & $1(0.7)$ & $1(0.6)$ & - & - \\
\hline Genotype not determined & $1(3.8)$ & $7(5)$ & $8(4.8)$ & - & - \\
\hline Total & $26(100)$ & $141(100)$ & $167(100)$ & - & - \\
\hline
\end{tabular}

$a$ : intermediate and rapid acetylators were grouped into the same class and used as reference for odds ratio (OR) and $95 \%$ confidence interval (CI) calculation. Individuals with not determined acetylation status were excluded from phenotype analysis. 
azid is lower in slow than in rapid acetylators (Sarma et al. 1986, Fukino et al. 2008). All of these drug disposal processes may support the finding that slow acetylators are prone to INH-induced hepatitis.

Few studies have reported the absence of a relationship between acetylation status and hepatitis during TB treatment (Singh et al. 1995a, b, Vuilleumier et al. 2006) or observed that rapid acetylators could be susceptible to this type of side effect (Mitchell et al. 1975). Here, genotyping of the NAT2 gene was performed by sequencing, overcoming the possible problems of misclassification of the acetylation status. Another important aspect to be considered here is that in our study, patients were treated with $400 \mathrm{mg}$ of INH instead of the $300 \mathrm{mg}$ used in the study conducted by Vuilleumier et al. (2006).

CYP2E1, one of the cytochrome P450 enzymes, may convert acetylhydrazine into hepatotoxins that affect anti-TB drug-induced hepatotoxicity. Some studies have shown the relationship between the $C Y P 2 E 1^{*} 1 \mathrm{~A} / * 1 \mathrm{~A}$ genotype and the risk of anti-TB drug-induced hepatitis (Huang et al. 2003, Vuilleumier et al. 2006). However, a recent study in a Korean population did not confirm those results (Cho et al. 2007). In the studied population, in contrast with the findings for the Taiwanese population (Huang et al. 2003), the mutant homozygous CYP2E1 *5/*5 is rare ( $0.5 \%$ vs. $4.7 \%$, respectively) (Sigimura et al. 1995, Huang et al. 2003). Indeed, we found only one individual with $C Y P 2 E 1 * 5 / * 5$ genotype among the 167 patients enrolled in this study $(0.6 \%)$ with no association between the CYP2E1 genotypes and hepatic side effect occurrence. The discrepancy of our results may be due to the differences in the frequencies of wild-type $C Y P 2 E 1 * 1 A$ and mutant $C Y P 2 E 1 * 5$ alleles among Brazilian individuals. Therefore, further studies with a larger sample size should be performed in the Brazilian population to better evaluate the relationship between the CYP2E1 genotypes and adverse reactions during TB treatment.

Finally, the frequencies of homozygous GSTM1 and GSTT1 null genotypes in this study were in accordance with other studies in a Brazilian population (SuarezKurtz et al. 2007), showing the consistency of our data. Few studies have observed the relationship between GST genotypes and anti-TB drug-induced hepatotoxicity (Roy et al. 2001, Huang et al. 2007, Leiro et al. 2008). Indeed, Roy et al. (2001) have observed a significant association between the homozygous GSTM1 null polymorphism and the anti-TB drug-induced hepatotoxicity in Indian TB patients. Recently, Huang et al. (2007) have found similar results in a Chinese population. In contrast, the presence of the homozygous GSTT1 null polymorphism was similar between the cases and the controls in both studies. However, the same analysis in Spanish TB patients showed an opposite effect; the homozygous GSTT1 null polymorphism was highly associated with anti-TB drug-induced hepatotoxicity and no significant associations were found between the homozygous GSTM1 null polymorphism and hepatotoxicity (Leiro et al. 2008). Therefore, further studies should be performed to evaluate the role of these genetic factors in the susceptibility to hepatitis occurrence.
To our knowledge, this is the first study in which the four candidate genes, which are known to be involved in the INH metabolic pathway, were evaluated simultaneously as risk factors for anti-TB drug-induced hepatitis in an admixed population. Here, the decision to exclude other variables that are potentially associated with hepatitis was pursued to confirm the association of genetic factors with the key outcome.

Genotyping interindividual variability at the NAT2 locus as an additional laboratory tool to predict antiTB drug-induced hepatitis and other side effects is an emerging reality and will help not only in the determination of the most suitable dosage for individual patients, but also in the reduction of necessary outpatient visits and hospitalisations.

\section{ACKNOWLEDGEMENTS}

To the nursing service of the Hospital Tuberculosis Control Program/Thoracic Diseases Institute/Clementino Fraga Filho University Hospital, for sample collection, and for the support from the PDTIS-FIOCRUZ sequencing and Bioinformatics Platforms.

\section{REFERENCES}

Bailey LR, Roodi N, Verrier CS, Yee CJ, Dupont WD, Parl FF 1998. Breast cancer and CYP1A1, GSTM1 and GSTT1 polymorphisms: evidence of a lack of association in Caucasians and African Americans. Cancer Res 58: 65-70.

Chen B, Zhang WX, Cai WM 2006. The influence of various genotypes on the metabolic activity of NAT2 in Chinese population. Eur J Clin Pharmacol 62: 355-359.

Cho HJ, Koh WJ, Ryu YJ, Ki CS, Nam MH, Kim JW, Lee SY 2007. Genetic polymorphisms of NAT2 and CYP2E1 associated with antituberculosis drug-induced hepatotoxicity in Korean patients with pulmonary tuberculosis. Tuberculosis (Edinb) 87: 551-556.

Ellard GA, Gammon PT 1976. Pharmacokinetics of isoniazid metabolism in man. J Pharmacokinet Biopharm 4: 83-113.

Fountain FF, Tolley E, Chrisman CR, Self TH 2005. Isoniazid hepatotoxicity associated with treatment of latent tuberculosis infection: a 7-year evaluation from a public health tuberculosis clinic. Chest 128: 116-123.

Fretland AJ, Leff MA, Doll MA, Hein DW 2001. Functional characterization of human $\mathrm{N}$-acetyltransferase 2 (NAT2) single nucleotide polymorphisms. Phamacogenetics 11: 207-215.

Frieden TR, Sterling TR, Munsiff SS, Watt CJ, Dye C 2003. Tuberculosis. Lancet 362: 887-899.

Fukino K, Sasaki Y, Hirai S, Nakamura T, Hashimoto M, Yamagishi F, Ueno K 2008. Effects of NAT2, CYP2E1 and GST genotypes on the serum concentrations of isoniazid and metabolites in tuberculosis patients. $J$ Toxicol Sci 33: 187-195.

Garibaldi RA, Drusin, RE, Ferebee, SH, Gregg MB 1972. Isoniazidassociated hepatitis. Report of an outbreak. Am Rev Respir Dis 106: 357-365.

Hayes JD, Flanagan JU, Jowsey IR 2005. Glutathione transferases. Annu Rev Pharmacol Toxicol 45: 51-88.

Hiratsuka M, Kishikawa Y, Takekuma Y, Matsuura M, Narahara K, Inoue T, Hamdy SI, Endo N, Goto J, Mizugaki M 2002. Genotyping the $\mathrm{N}$-acetyltransferase 2 polymorphism in the prediction of adverse drug reactions to isoniazid in Japanese patients. Drug Metab Pharmacokinet 17: 357-362.

Huang YS, Chern HD, Su WJ, Wu JC, Chang SC, Chiang CH, Chang FY, Lee SD 2003. Cytochome P4502E1 genotype and the sus- 
ceptibility to antituberculosis drug-induced hepatitis. Hepatology 37: 924-930.

Huang YS, Chern HD, Su WJ, Wu JC, Lai SL, Yang SY, Chang FY, Lee SD 2002. Polymorphism of the N-acetyltransferase 2 gene as a susceptibility risk factor for antituberculosis drug-induced hepatitis. Hepatology 35: 883-889.

Huang YS, Su WJ, Huang YH, Chen CY, Chang FY, Lin HC, Lee SD 2007. Genetic polymorphisms of manganese superoxide dismutase, NAD(P)H:quinine oxidoreductase, glutathione S-transferase M1 and $\mathrm{T} 1$ and the susceptibility to drug-induced liver injury. J Hepatol 47: 128-134.

Kimmoun E, Samuel D 2002. Antituberculous drugs in patients with chronic liver disease. J Gastroenterol Hepatol 17: 408-412.

Kinzig-Schippers M, Tomalik-Scharte D, Jetter A, Scheidel B, Jakob V, Rodamer M, Cascorbi I, Doroshyenko O, Sörgel F, Fuhr U 2005. Should we use $\mathrm{N}$-acetyltransferase type 2 genotyping to personalize isoniazid doses? Antimicrob Agents Chemother 49: 1733-1738.

Kita T, Tanigawara Y, Chikazawa S, Hatanaka H, Sakaeda T, Komada F, Iwakawa S, Okumura K 2001. N-acetyltransferase 2 genotype correlated with isoniazid acetylation in Japanese tuberculous patients. Biol Pharm Bull 24: 544-549.

Lauterburg BH, Smith CV, Todd EL, Mitchell JR 1985. Pharmacokinetics of the toxic hydrazine metabolites formed from isoniazid in humans. J Pharmacol Exp Ther 235: 566-570.

Lee WM 2003. Medical progress: drug-induced hepatotoxicity. N Engl J Med 349: 474-485.

Leiro V, Fernández-Villar A, Valverde D, Constenla L, Vázquez R, Piñeiro L, González-Quintela A 2008. Influence of glutathione S-transferase M1 and T1 homozygous null mutations on the risk of antituberculosis drug-induced hepatotoxicity in Caucasian population. Liver Int 28: 835-839.

Li N, Stephens M 2003. Modeling linkage disequilibrium and identifying recombination hotspots using single nucleotide polymorphism data. Genetics 165: 2213-2233.

Mitchell JR, Snodgrass WR, Gillette JR 1976. The role of biotransformation in chemical-induced liver injury. Environ Health Perspect 15: 27-38.

Mitchell JR, Thorgeisson UP, Black M Timbrell JA, Snodgrass WR, Potter WZ, Jollow HR, Keiser HR 1975. Increased incidence of isoniazid hepatitis in rapid acetylators: possible relation to hydralazine metabolites. Clin Pharmacol Ther 18: 70-79.

MS - Ministério da Saúde, Brazil 2007. National politics of TB control, MS, Brasília, 43 pp.

Nelson SD, Mitchell JR, Timbrell JA, Snodgrass WR, Corcoran GB 1976. Isoniazid and iproniazid: activation of metabolites to toxic intermediates in man and rat. Science 193: 901-903.

Ohno M, Yamaguchi I, Yamamoto I, Fukuda T, Yokota S, Maekura R, Ito M, Yamamoto Y, Ogura T, Maeda K, Komuta K, Igarashi T, Azuma J 2000. Slow N-acetyltransferase 2 genotype affects the incidence of isoniazid and rifampicin-induced hepatotoxicity. Int J Tuberc Lung Dis 4: 256-261.

Parkin DP, Vandenplas S, Botha FJ, Vandenplas ML, Seifart HI, van Helden PD, van der Walt BJ, Donald PR, van Jaarsveld PP 1997. Trimodality of isoniazid elimination: phenotype and genotype in patients with tuberculosis. Am J Respir Crit Care Med 155: 1717-1722.

Roy B, Chowdhury A, Kundu S, Santra A, Dey B, Chakraborty M, Majumder PP 2001. Increased risk of antituberculosis drug-induced hepatotoxicity in individuals with gluthatione S-transferase M1 "null" mutation. J Gastroenterol Hepatol 16: 1033-1037.
Roy B, Ghosh SK, Sutradhar D, Sikdar N, Mazumder S, Barman S 2006. Predisposition of antituberculosis drug induced hepatotoxicity by cytochrome P450 2E1 genotype and haplotype in pediatric patients. J Gastroenterol Hepatol 21: 784-786.

Roy PD, Majumder M, Roy B 2008. Pharmacogenomics of anti-TB drugs-related hepatotoxicity. Pharmacogenomics 9: 311-321.

Salpeter SR 1993. Fatal isoniazid-induced hepatitis. Its risk during chemoprophylaxis. West J Med 159: 560-564.

Santos-Filho ET 2006. Public Health Watch. TB politics in Brazil - A perspective of civil society, Open Society Institute, Rio de Janeiro, $85 \mathrm{pp}$.

Sarma GR, Immanuel C, Kailasam S, Narayana AS, Venkaresan P 1986. Rifampin-induced release of hydrazine from isoniazid. A possible cause of hepatitis during treatment of tuberculosis with regimens containing isoniazid and rifampin. Am Rev Respir Dis 133: 1072-1075.

Saukkonen JJ, Cohn DL, Jasmer RM, Schenker S, Jereb JA, Nolan CM, Peloquin CA, Gordin FM, Nunes D, Strader DB, Bernardo J, Venkataramanan R, Sterling TR, ATS (American Thoracic Society) Hepatotoxicity of Antituberculosis Therapy Subcommittee 2006. An official ATS statement: hepatotoxicity of antituberculosis therapy. Am J Respir Crit Care Med 174: 935-952.

Sigimura H, Hamada GS, Suzuki I, Iwase T, Kiyokawa E, Kino I, Tsugane S 1995. CYP1A1 and CYP2E1 polymorphism and lung cancer, case-control study in Rio de Janeiro, Brazil. Pharmacogenetics 5: S145-148.

Singh J, Arora A, Garg PK, Thakur VS, Pande JN, Tandon RK 1995a. Antituberculosis treatment-induced hepatotoxicity: role of predictive factors. Postgrad Med J 71: 359-362.

Singh J, Garg PK, Thakur VS, Tandon RK 1995b. Antitubercular treatment induced hepatotoxicity: does acetylator status matter? Indian J Physiol Pharmacol 39: 43-46.

Sodhi CP, Rana SV, Mehta SK, Vaiphei K, Attri S, Thakur S, Mehta S 1996. Study of oxidative stress in isoniazid-induced hepatic injury in young rats with and without protein-energy malnutrition. J Biochem Toxicol 11: 139-146.

Sprenger R, Schlagenhaufer R, Kerb R, Bruhn C, BrockmoÈller J, Roots I, Brinkmann U 2000. Characterization of the glutathione S-transferase GSTT1 deletion: discrimination of all genotypes by polymerase chain reaction indicates a trimodular genotypephenotype correlation. Pharmacogenetics 10: 557-565.

Steele MA, Burk RF, Desprez RM 1991. Toxic hepatitis with isoniazid and rifampin. A meta-analysis. Chest 99: 465-471.

Stephens EA, Taylor JA, Kaplan N, Yang CH, Hsieh LL, Lucier GW, Bell DA 1994. Ethnic variation in the CYP2E1 gene: polymorphism analysis of 695 African-Americans, European-Americans and Taiwanese. Pharmacogenetics 4: 185-192.

Stephens M, Donnelly P 2003. A comparison of Bayesian methods for haplotype reconstruction. Am J Hum Genet 73: 1162-1169.

Stephens M, Smith NJ, Donnelly P 2001. A new statistical method for haplotype reconstruction from population data. Am J Hum Genet 68: 978-989.

Suarez-Kurtz G, Vargens DD, Struchiner, CJ, Bastos-Rodrigues L, Pena SDJ 2007. Self-reported skin color, genomic ancestry and the distribution of GST polymorphisms. Pharmacogenet Genomics 17: 765-771.

Teixeira RL, Miranda AB, Pacheco AG, Lopes MQ, Fonseca-Costa J, Rabahi MF, Melo HM, Kritski AL, Mello FC, Suffys PN, Santos AR 2007. Genetic profile of the arylamine N-Acetyltransferase 2 coding gene among individuals from two different regions of Brazil. Mutat Res 624: 31-40. 
Teixeira RL, Silva Jr FP, Silveira AR, Cabello PH, Mendonça-Lima L, Rabahi MF, Kritski AL, Mello FC, Suffys PN, de Miranda AB, Santos AR 2010. Sequence analysis of NAT2 gene in Brazilians: identification of undescribed single nucleotide polymorphisms and molecular modeling of the $\mathrm{N}$-acetyltransferase 2 protein structure. Mutat Res 683: 43-49.

Timbrell JA, Mitchell JR, Snodgrass WR, Nelson SD 1980. Isoniazid hepatotoxicity: the relationship between covalent binding and metabolism in vivo. J Pharmacol Exp Ther 213: 364-369.

Timbrell JA, Wright JM, Baillie TA 1977. Monoacetylhydrazine as a metabolite of isoniazid in man. Clin Pharmacol Ther 22: 602608.

Tostmann A, Boeree MJ, Aarnoutse RE, de Lange WC, van der Ven AJ, Dekhuijzen R 2008. Antituberculosis drug-induced hepatotoxicity: concise up-to-date review. J Grastroenterol Hepatol 23: 192-202.
Vuilleumier N, Rossier MF, Chiappe A, Degoumois F, Dayer P, Mermillod B, Nicod L, Desmeules J, Hochstrasser D 2006. CYP2E1 genotype and isoniazid-induced hepatotoxicity in patients treated for latent tuberculosis. Eur J Clin Pharmacol 62: 423-429.

WHO - World Health Organization 2008. Global tuberculosis control. WHO Report 2008. Available from: who.int/tb/publications/ global_report/2008/en/index.html.

Woodward KN, Timbrell JA 1984. Acetylhidrazine hepatotoxicity: the role of covalent binding. Toxicology 30: 65-74.

Yew WW, Leung CC 2006. Antituberculosis drugs and hepatotoxicity. Respirology 11: 699-707.

Zang Y, Doll MA, Zhao S, States JC, Hein DW 2007. Functional characterization of single-nucleotide polymorphisms and haplotypes of human N-acetyltransferase 2. Carcinogenesis 28: 1665-1671. 